\title{
İç Denetimde Yapısal Değişim ve Dönüşüm: İç Denetçilerin Farkındalığı ve Beklentileri Üzerine Bir Araştırma
}

\section{Structural Change and Transformation in Internal Audit: A Research on Awareness and Expectations of Internal Auditors}

\author{
N. Gözde Bircan ${ }^{1}(\mathbb{0}$ \\ ${ }^{1}$ Öğretim Görevlisi, T.C. İstanbul Kültür Üniversitesi, İşletme Yönetimi Programı, İstanbul, Türkiye \\ ORCID: N.G.B: 0000-0002-0217-6339
}

\section{ÖZ}

İç denetim, ağırlıklı olarak kurum içi denetim çalışmalarını yürüten, işletmedeki iç kontrol sistemi ile karşılıklı etkileşim içinde olan, bağımsız denetime yaptığı çalışmalarla destek sağlayan ve aynı zamanda kurumsal risk yönetimi, yönetişim ve kontrol süreçlerini de içeren bir denetim ve danışmanlık faaliyetidir. Günümüz Dünyasında meydana gelen değişimler ile birlikte standart iç denetim kavramı ve iç denetimden beklentiler değişmiş, buna bağlı olarak iç denetim faaliyetlerinin kapsamı ile iç denetçilerin sorumlulukları da genişlemiştir. Çalışmamızda iç denetimin tarihsel süreç içerisinde gösterdiği değişimden hareketle iç denetimin değişen rolü, değişen iç denetim faaliyetleri ve değişen iç denetçi profilleri iç denetçilerin algısı ve beklentileri üzerinden anket yöntemi ile değerlendirilmiş ve iç denetimde meydana gelen yapısal değişim ve dönüşüm açıklanmıştır.

Anahtar kelimeler: Denetim, iç denetim, iç denetçi, değişim, dönüşüm

\section{ABSTRACT}

Internal auditing is a process of auditing and administration which mainly involves doing audits internally and is directly affected by internal control and interacting with it, supporting external audit with its work and containing process of corporate risk management, governance and control at the same time. The matter of internal audit and expectations from that profession have changed and therefore the scope of internal auditing and responsibilites of internal auditors have broadened as a consequence of changes and developments in today's world. In this study, the new role of internal auditing, new internal audit activities and new internal auditors have been considered and examined using a survey of perceptions and expectations of internal auditors regarding changes in internal auditing in historical processes.

Keywords: Auditing, internal audit, internal auditor, change, transformation

Başvuru/Submitted: 15.05.2020 Revizyon Talebi/Revision Requested: 22.06.2020 Son Revizyon/Last Revision Received: 25.06 .2020 Kabul/Accepted: 15.07.2020 Sorumlu yazar/Corresponding author: N.Gözde Bircan / g.bircan@iku.edu.tr 


\section{Extended Abstract}

According to the International Professional Practices Framework issued by the Chartered Institute of Internal Auditors (IIA), "internal auditing is an independent, objective assurance and consulting activity which is designed to add value and improve operations of organizations". The definition of internal auditing by the IIA, comprises evaluating and improving risk managementand the control and governance process of organizations including the role of assurance and consulting. However, important changes and new developments happening in today's world have changed traditional definitions of internal auditing and, importantly, expectations from it. Also, the scope of internal auditing and responsibilites of internal auditors have broadened as a consequence of these changes and developments.

The Institute of Internal Auditors (IIA), has provided new mandatory guidance for internal auditors for complying with the changing expectations of today's world. A new role and a new responsibility has come in sight for the profession with each new guidance issued by The Institute of Internal Auditors (IIA). In this context, much more than ever is expected of internal auditors. Today, internal auditors are responsible for considering fraud risks, corporate culture risks, and cyber risks synchronously alongside their routine auditing processes. Therefore, internal auditors have to have a through understanding of the corporate culture of their organizations, know new Technologies, understand any possible cyber risks which arise from them and have sufficient information to evaluate the risks of fraud in organizations. So, the changes in internal auditing are far beyond auditing effectiveness and efficiency of internal controls in organizations - in contrast to how it used to be before. All of these increasing and continuous changes and developments in the profession, have forced internal auditors to develop their knowledge, skills and add value to their self-competence for meeting the new requirements expected of them. The internal auditors of the future must have abilities like using robotic software and artificial intelligence, analytical thinking, anticipating, having good communication skills, detecting various risks, being open-mided, being innovative, being dynamic, being fast and so on.

Success of the profile of future internal audit and future internal auditors is considerably related to the awareness and expectations of internal auditors about the future internal audits, because they are the main actors in the profession. Thus, making therequired changes and transformation in real terms for the profession, will probably vary by how much internal auditors are aware of it, how strong they believe it and what kind of expectations they have for the process of change and transformation. This study focuses on measuring and evaluating the process of structural change and transformation in internal audit from the side of internal auditors'. The new and changing role of internal auditing, new internal audit activities and the new profile of internal auditors have been considered and examined using a survey based on perceptions and expectations of internal auditors regarding changes in internal auditing in historical processes. Fifty-one internal auditors participated in the survey and answered the survey quesions. The results of the survey showed that there is a certain and clear mental change and awareness in internal auditors in terms of supporting the fact of change and transformation in the profession. However, when it comes to appyling them completely in practice, there are some deficiencies regarding developing existing skills and abilities of internal auditors and supporting them by their management. Change and transformation in internal audit is an undeniable fact. Reflecting the changes and developments around the profession, the future internal auditors must firstly change themselves and then adapt to new requirements quickly by developing their skills and abilities. In this respect, a supportive approach by their management is very important for both the success of internal audits and the succees of organizations too. 


\section{Giriş}

Günümüz Dünyasında yaşanan bilişsel ve teknolojik gelişmeler, denetim biliminde geleneksel veya standart nitelikteki yaklaşımların yerini geleceğe yönelik, risk odaklı, daha güncel ve dijital nitelikteki yeni denetim anlayışlarına bırakmasını zorunlu kılmıştır. Yaşanan değişim ve gelişmelerden en çok etkilenen denetim türlerinden biri de iç denetim olmuştur.

İç denetim bilinen en eski ve basit tanımıyla; bir organizasyon içerisinde işletmenin çalışanı olarak yer alan iç denetçi veya iç denetçiler tarafından yapılan denetimdir. Bu tanım bize iç denetimin işletme içerisindeki kişiler tarafından yapıldığını göstermekte, iç denetçi adı verilen bu kişiler tarafından yapılan iç denetim faaliyetinin kapsamı hakkında herhangi bir detay vermemekte ve standart nitelikteki bir iç denetim faaliyetine işaret etmektedir.

Zaman içerisinde işletmelerin faaliyet konularının genişlemesi, işlem hacimlerinin büyümesi, suistimal içerikli hile skandallarının artması ile birlikte iç denetimin faaliyet kapsamının; risk ve suistimal odaklı, işletme içerisindeki kurumsal kültür, yönetişim, kontrol vb. gibi süreçlerin etkinliğini eş zamanlı olarak değerlendiren, denetim hizmetine ek olarak danışmanlık ve güvence hizmeti de sağlayan şekilde genişlediği, sadece kurum içi çalışanlar tarafından yapılan değil kurum dışından da alınabilen bir denetim hizmeti haline dönüştüğü ve standart nitelikteki bir iç denetim anlayışından risk odaklı bir iç denetim anlayışına geçildiği görülmektedir.

Özellikle son yıllarda yaşanan yeni teknolojik ve bilişsel değişimlerle birlikte ise işletmelerde robotik süreçlere yer verilmesi, yapay zeka uygulamaları, büyük verinin doğuşu ve kullanılan yeni teknolojilere paralel olarak ortaya çıkan siber riskler, iç denetim anlayışında risk odaklı iç denetimin de ötesinde köklü bir değişim ve dönüşüm ihtiyacını ortaya çıkarmıştır. Türkiye'de iç denetim konusunda en önemli kuruluşlardan biri olan Türkiye İç Denetim Enstitüsü (TIDE) tarafından 21-22 Ekim 2019 tarihlerinde gerçekleştirilen XXIII. Uluslararası Türkiye İç Denetim Kongresinde de "Günümüz Dünyasında Değişimin Öncüsü Olmak” temasıyla iç denetimdeki bu değişim ve dönüşüm ihtiyacına vurgu yapılmış ve küresel değişim şartlarının gerektirdiği yeni yetkinliklerin, iç denetçilere kazandırılmasının önemi üzerinde durulmuştur.

Bilişsel çağda ve teknolojide meydana gelen sürekli değişimler ile birlikte işletmelerde geleneksel iş modellerinin yerini dijital iş modellerine bırakması, yapısal olarak iç denetim faaliyetini yakından etkilemiş ve standart iç denetim anlayışından farklı yeni bir iç denetim anlayışııı beraberinde getirmiştir.

İç denetimde gerçekleşen bu yapısal değişim ve dönüşüm temelde; kurumsal değişim ve dönüşüm, dijital değişim ve dönüşüm ve kültürel değişim ve dönüşüm olmak üzere üç başlık altında ele alınabilir.

\section{Literatür İncelemesi}

Günümüz Dünyasının değişen dinamikleri, bilgi ve bilişim teknolojisinde yaşanan değişimler ve bu değişimlerin denetim mesleğine olan etkileri sonucunda, özellikle 2010 yılı ve sonraki yıllardan itibaren iç denetim mesleği de sürekli bir değişim ve dönüşüm sürecinin içerisine girmiştir. Sürekli değişim atmosferi içerisinde denetim alanında özellikle iç denetim mesleğinde gerçekleşen değişimin ihtiyaçlarına cevap verebilecek şekilde yeni düzenlemelerin, yapılandırmaların ve reformların oluşturulması ve uygulanması bir gereklilik haline gelmiştir.

İç denetimin yapısında gerçekleşen bu değişim ve dönüşüm süreci ilk olarak, iç denetim konusunda resmi olarak mesleki yeterlilikleri ve standartları belirleme yetkisine sahip, iç denetim mesleğinin gelişiminde ve ilerlemesinde temel rol oynayan uluslararası profesyonel bir kuruluş olan Uluslararası İç Denetçiler Enstitüsü (IIA) tarafından iç denetçiler için yayınlanan mesleki raporlar, mesleki rehberler ve bildirilerle başlamıştır.

Uluslararası İç Denetçiler Enstitüsü (IIA) 2014 yılında yayınlamış olduğu "Kültür ve İç Denetimin Rolü" adlı raporda; yaşanan muhasebe skandallarında iç kontrol ve iç denetim eksikliklerinin yanı sıra organizasyonlar içerisindeki zayıf veya kötü kurumsal kültür yapısının önemli bir faktör olduğunu, bu noktada iç denetçilerin kurumsal kültürü denetlenebilir hale getirilmesi konusunda yetkinlikler geliştirmesi gerektiğini ve işletme yönetimlerine organizasyonun kurumsal kültürünün iyileştirilmesi konusunda gerekli desteği sağlamaları gerektiğini vurgulamıştır. 2017 yılında ise Clemens ve Rick (2017, s.62) 
tarafından yapılan çalışmada, iç denetim fonksiyonunun kurumsal kültür ile olan yakın ilişkisi "iliş̧i yönetimi” adı verilen döngüde 4 aşamalı bir süreç olarak ele alınmış ve döngünün ilişki yönetimi bölümünde iç denetimin, periyodik olarak organizasyonun tepe yönetimi yöneticileriyle çeşitli toplantılar yaparak organizasyonun kurumsal kültür dinamiklerini (misyon, vizyon, değerler, davranış ve tutumlar) değerlendirdiği, gözden geçirdiği ve kontrol altına alınmasını sağladığı belirtilmiştir. Uluslararası İç Denetçiler Enstitüsü (IIA) tarafından yayınlanan 7 Ekim 2019 tarihli denetim komitesi açılamasında da iç denetim açısından kurumsal kültür konusunda aynı vurgu yapılmış ve organizasyon içerisindeki kurumsal kültürün güvenilirliği konusunda iç denetçilerin kilit bir rol oynadığı ifadesine yer verilmiştir. (The Instittute of Internal Auditors [IIA], 2019) Böylelikle iç denetimin yeni faaliyet konularından biri de kurumsal kültürün denetlenmesi olarak ortaya çıkmış ve iç denetimde kültürel bir değiş̧im ve dönüşüm süreci mesleğin bir gerekliliği haline gelmiştir.

İç denetimde meydana gelen ve yukarıda yer verilen kültürel değişimler, 2017 yılında yayınlanan yeni COSO iç kontrol bütünleşik çerçevesi ile daha da geniş bir boyuta ulaşmıştır. Yeni iç kontrol bütünleşik çerçevesinde, iç denetimi yakından ilgilendiren iç kontrol sisteminin ana bileşenleri; "yönetişim ve kültür", "strateji ve hedef belirleme", "performans", "gözden geçirme ve düzenleme" ile "bilgi, iletişim ve raporlama" olarak beş farklı grupta sınıflandırılmıştır. Böylelikle kurumsal yönetimi yakından ilgilendiren yönetişim ve kültür kavramları bir arada, iç kontrol sisteminin yeni ana bileşenleri olarak iç kontrol bütünleşik çerçevesine eklenmiştir. COSO'da meydana gelen değişimlere paralel olarak Adiloğlu ve Öner (2019, s.81) iç denetimi, kurumsal risk yönetimi açısından farklı bir bakış açısı olan $5 \mathrm{~S}$ yaklaşımı ile değerlendirmiş, kurumsal yönetimin iç denetimle bütünleşik olarak hareket etmesi gereken bir süreç olduğunu ve risk odaklı bir iç denetimin öncelikle organizasyon içerisinde tasarlanmış iyi bir kurumsal yönetimle mümkün olabileceğini vurgulamıştır. Tüm bunlar değişen iç kontrol sisteminin işlerliğini ve etkinliğini değerlendirebilmek için iç denetim fonksiyonunda da kültürel değişimle paralel kurumsal bir değişim ve dönüşüm sürecini beraberinde getirmiştir.

2010 y1lı ve sonrasında organizasyonlarda yaşanan kurumsal ve kültürel tabanlı değişimlerle birlikte yeni bilişsel teknolojilerin işletmelerin içerisinde yer alması sonucunda iç denetimin faaliyet alanlarından biri de dijital unsurlar konusunda gerekli yetkinliklerin kazanılarak dijital suiistimallerin denetlenmesi olmuştur. McCollum (2012, s.13) dijital suçlarla ilgili çalışmasında dijital hilelerin, en riskli muhasebe hileleri açısından 4. sırada yer aldığını ve işletmelerde dijital hilelerin önlenmesi konusunda iç denetçilere önemli bir sorumluluk düştüğünü vurgulamıştır. Mocollum'un çalışmasını destekleyici şekilde Uluslararası İç Denetçiler Enstitüsü (IIA) tarafından yayınlanan yeni mesleki rehberler, raporlar ve standartlarda da iç denetçilere yeni dijital yetkinliklerin kazandırılması konusuna yer verilmiş ve bunun iç denetimin faaliyetine devam edebilmesi için bir gereklilik olduğu vurgulanmıştır. Tüm bunlar, iç denetim mesleğinin kurumsal ve kültürel değişime paralel olarak dijital anlamda da bir değişim ve dönüşüm sürecine girdiğini göstermektedir.

\section{3. İç Denetim Kavramı}

Denetim faaliyeti temel olarak; mali tabloların bağımsız denetimi, faaliyet denetimi ve uygunluk denetimi olmak üzere üç gruba ayrılmaktadır. Bu sınıflandırmaya göre iç denetim, temel denetim türlerinden uygunluk denetimi ve faaliyet denetiminin kapsamına girmektedir ve işletme içerisinde iç denetçiler uygunluk ve faaliyet denetimi yapmaktadırlar. Organizasyonlar içerisinde iç denetim faaliyetleri gerekli mesleki yetkinliğe sahip uzman iç denetçiler tarafından yapılmaktadır.

Türkiye İç Denetim Enstitüsü (TIDDE) tarafından yapılan tanımlamada iç denetim; "bir kurumun faaliyetlerini gelişstirmek ve onlara değer katmak amacını güden bağımsız ve objektifbir güvence ve danışmanlık faaliyeti” "şeklinde tanımlanmaktadır. (Türkiye İç Denetim Enstitüsü [TIDE], 2010) TİDE tarafından yapılan tanımlama doğrultusunda kurumun risk yönetim, kontrol ve yönetişim süreçlerinin etkililiğini değerlendirmek, geliştirmek ve kurumun amaçlarına ulaşmasına yardımcı olmak iç denetimin temel amaçlarını oluşturmaktadır. Buna göre iç denetim, işletmelerin amaçlarına ulaşmasında başarılı olmasında kilit bir rol oynamaktadır.

İç denetimin en önemli fonksiyonlarından biri kurum içerisindeki iç kontrol sistemlerinin etkinliğini değerlendirmektir. İşletme içerisindeki iç kontrollerin yeterliliği ve işlerliği iç denetim mekanizması tarafından denetlenmektedir ve iç 
kontrollerin başarısı iç denetim tarafından ölçülmektedir. İç denetim faaliyeti, kurum içerisindeki kontrollerin etkinliğini ölçmeyi ve değerlendirmeyi hedef almaktadır. Bu yönüyle iç denetim işletmeler için aynı zamanda önemli bir yönetim kontrol aracıdır (Güredin, 2014, s.20).

İşletme içerisinde iç denetim ve iç kontrol karşılıklı olarak birbirini etkileyen ve yakın ilişki içerisinde olan fakat, birbirinden farklı olan kavramlardır. Başarılı bir iç denetim için gerekli olan kontrol mekanizmalarının oluşturulması ve uygulanması işletme içerisindeki iç kontrol sistemi tarafından sağlanmaktadır. İç denetim ise söz konusu iç kontrollere yönelik çeşitli değerlendirmeler yaparak işletme yönetimine bilgi vermekte ve önerilerde bulunmaktadır. Buna göre iç denetimin iç kontrolün bağımsız bir fonksiyonu olduğu ve iç kontrol süreçlerinin etkinliğinin ve başarısının iç denetim tarafından değerlendirildiği söylenebilir (Sabuncu, 2017, s.161).

İç denetim, diğer denetim türlerinden farklı olarak işletmelerde yönetim adına yapılan bir denetim faaliyetidir ve işletme içerisinde iç denetçiler yönetim adına çeşitli denetim faaliyetlerinde bulunmaktadır (Bozkurt, 2010, s.134). Nitekim iç denetimin temel sorumluluk alanlarından biri olan uygunluk denetimi çalışmalarının kapsamında iç denetçiler, ağılıklı olarak işletme tepe yöneticileri tarafından konulan etik kurallara, ilkelere, işletme içerisinde düzenlenmiş politika ve prosedürlere işletme çalışanları tarafından uyulup uyulmadığını değerlendirmektedir.

Benzer şekilde faaliyet denetimi çalışmaları kapsamında iç denetçiler, işletmelerin amaçlarına ulaşmada kaynaklarını etkin ve verimli kullanıp kullanmadığını değerlendirmek amacıyla işletme yönetimi için önemli bir karar mekanizması ve performans değerlendirme ölçütü olan bütçeler, başarı ölçüleri, anahtar performans göstergeleri vb. gibi işletme yönetimi tarafından önceden belirlenmiş olan çeşitli ölçütleri kullanırlar.

İç denetim faaliyetinin işletme yönetime yakın bir denetim faaliyet olması iç denetime, işletme yönetimi ve bağımsız denetim faaliyeti arasında bir köprü işlevine sahip olma özelliğini kazandırmaktadır. İç denetim tarafından yapılan çalışmalar bağımsız denetim faaliyetine de ciddi bir katkı sağlamaktadır. İç denetim çalışmalarına ilişkin materyaller iç denetimin bağımsızlığı, iç denetçilerin yeterliliği ve iç denetim çalışmalarının kalitesi test edilmek şartıyla bağımsız denetim tarafından da kullanılabilmektedir veya bağımsız denetçiler denetim çalışmalarında iç denetçilerle çeşitli konularda iş birliği yapabilmektedir. Bununla birlikte iç denetimin yönetime yakın bir denetim faaliyeti olması ve işletmelerde iç denetimin genellikle işletme tarafından istihdam edilen işletme içi çalışanlar tarafından yapılması iç denetimin bağımsızlığı açısından ciddi bir tehlike oluşturmaktadır. Denetim kavramının doğası gereği gerçek bir iç denetim faaliyetinden söz edebilmek için işletme içerisinde iç denetimin bağımsızlı̆̆ının tam olarak sağlanmış olması gerekmektedir.

İç denetim faaliyetleri bir organizasyonunun başarılı olup olmamasında kritik bir öneme sahip bulunmaktadır. Günümüz Dünyasında başarılı olan organizasyonların temelinde geleceğe yönelik olarak tasarlanmış, geleceği öngörebilen ve işletmelerin değerini arttıran bir iç denetim fonksiyonu, önemli bir rol oynamaktadır. Bu şekilde tasarlanmış bir iç denetim fonksiyonu, işletmelere geleceğe yönelik olarak sürekli bir öngörü yeteneği sağlayarak işletmelere karşı tehdit oluşturan iş risklerinin yönetimi ve kontrolü açısından önemli bir güvence mekanizması oluşturmaktadır. (PricewaterhouseCoopers, [PwC], 2011)

\section{4. İç Denetimde Yapısal Değişim ve Dönüşüm}

Günümüzün küreselleşen Dünyasında yaşanan sosyal, kültürel, ekonomik ve teknolojik gelişmeler, iş yapış şeklinde meydana gelen değişiklikler, giderek dijitalleşen işs süreçleri ve bilişim teknolojisindeki yenilikler iç denetim faaliyetlerini yakından etkilemiş̧tir. Sürekli bir değişim ve dönüşüm sürecinde olan küresel Dünya şartları, iç denetimin öncelikle kendini yeni koşullara göre değiştirmesini ve dönüştürmesini zorunlu kılmıştır.

Değişen Dünya koşulları iç denetimin kapsamında, iç denetimin amaçlarında, iç denetime yönelik işletme yönetiminin beklentilerinde, iç denetçilerin profillerinde ve iç denetçilerin görev, yetki ve sorumluluklarının kapsamında dolayısıyla bir bütün olarak iç denetimin yapısında önemli değişikliklere neden olmuştur. 


\section{1. İç Denetimde Kurumsal Değişim ve Dönüşüm}

Kurumsal değişim ve dönüşüm, günümüz Dünyasında meydana gelen değişiklikler doğrultusunda işletmelerin kurumsal yönetiminde meydana gelen değişim ve dönüşümlerin iç denetimdeki yansımalarını ifade etmektedir.

Kurumsal yönetim; "bir yandan ekonomik ve sosyal hedefler arasında diğer yandan işletmenin hedefleri ile işletme çalışanlarının özellikle işletme yöneticilerinin hedefleri arasında denge sağlamak amacıyla alınabilecek önlemler ve bu önlemlerin, kullanılmasını zorunlu kıldiğı insan kaynakları, cihazlar, yöntem ve prosedürlerin tamamı" olarak tanımlanmaktadır (Aysan, 2007, s.18). Kurumsal yönetimin temel felsefesi; işletme ile ilgili tüm tarafların çıkarlarının korunmasına ve taraflar arasındaki adaletin sağlanmasına dayanmaktadır. Kurumsal yönetim kavramı dört temel ilkeye dayanmaktadır. Bunlar; adillik (şirket yönetiminin bütün hak sahiplerine karşı eşit davranmasının ifadesidir), şeffaflık, (şirketin kamuoyu ile doğru, açık ve karşılaştırılabilir şekilde bilgi paylaşmasını ifade eder), hesap verebilirlik (şirketin yönetim kurulunun, tepe yönetiminin performansını bağımsı bir şekilde izlemesini ve tepe yöneticilerinin hissedarlara karşı hesap verebilirliğinin temin edilmesini ifade eder) ve sorumluluk (şirketlerin hissedarları için değer yaratırken toplumsal değerleri yansitan kanun ve düzenlemelere uyum gösterecek şekilde faaliyet göstermesini) ilkeleridir (TKYD, 2020).

Günümüz işletmelerinin içerisinde bulunduğu atmosfer (büyük veriler, işlem hacimlerinin sürekli artması, iş ve süreçlerin giderek kompleks ve karmaşık hal alması, yeni teknolojilerin ve yapay zeka uygulamalarının kullanımı, bilgi hızındaki artış ve siber risklerin ortaya çıkışı) sebebiyle işletmelerin güçlü bir kurumsal yönetim sistemine ve bu sistemin değişen koşullara göre sürdürebilirliğinin sağlanmasına duyduğu ihtiyaç her geçen gün artmaktadır. Diğer bir deyişle günümüzde işletmelerin sürekliliklerini koruyabilmeleri ve başarılı olabilmelerinde güçlü bir kurumsal yönetime sahip olmak kilit rol oynamaktadır. Bu noktada işletmelerde iç denetim ve iç kontrol sistemlerine önemli bir rol düşmektedir. İç denetim ve iç kontrol sistemlerinin işletmelerde sağlam bir kurumsal yönetim alt yapısı oluşturabilmesi için ise değişen koşulların ihtiyacını karşılayacak şekilde yeniden tasarlanmalarına ihtiyaç duyulmaktadır. Nitekim bu ihtiyaçlar doğrultusunda revize edilen COSO iç kontrol bütünleşik çerçevesi ve kurumsal risk yönetim çerçevesi uyarınca iç kontrol bileşenleri ve iç kontrol açısından stratejik öneme sahip noktalar güncellenmiş ve bazı yapısal değişiklikler söz konusu olmuştur. 2017 yılında yayınlanan yeni düzenlemede iç kontrol sisteminin ana bileşenleri; "yönetişim ve kültür", "strateji ve hedef belirleme", "performans", "gözden geçirme ve düzenleme" ile "bilgi, iletişim ve raporlama" olarak beş grupta sınıflandırılmıştır (Karakaya, 2018, s.18). Buna göre değişen iç kontrol sisteminin ana bileşenleri incelendiğinde tüm bileşenlerin kurumsal yönetim kavramı ile yakın ilişkili olan kavramlar olduğu görülmektedir. Bu bileşenlerden özellikle yönetişim ve kültür bileşeni doğrudan kurumsal yönetimi ilgilendirmektedir.

Yönetişim ve kültür bileşeninin içeriği; yönetim kurulunun risk gözetimini uygulaması, operasyonel yapının oluşturulması, istenen/arzu edilen kültür yapısının tanımlanması, temel değerlere olan bağlılığın gösterilmesi ve kabiliyetli personelin kazanılması, geliştirilmesi ve elde tutulması gibi alt bileşenlerden oluşmaktadır. Söz konusu alt bileşenler kurumsal yönetim ilkelerinin temel yapı taşlarını oluşturmaktadır. Bu durum bize iç kontrol sistemlerinin odak noktalarından birinin işletmelerde güçlü bir kurumsal yönetim yapısı oluşturmak olduğunu göstermektedir. İç kontrol sistemlerindeki değişime paralel olarak işletmelerde iç kontrollerin etkinliğinin değerlendirilebilmesi için iç denetim sistemlerinin de kendisini değiştirmesi, yenilemesi ve değişen kurumsal yönetim ve iç kontrol sistemlerine göre kendisini dönüştürmesi gerekmektedir.

Kurumsal yönetim kavramının özü ve temel ilkeleri gereğince günümüz Dünyasında işletme içerisinde güçlü bir kurumsal yönetim sisteminin kurulabilmesi konusunda iç denetime eskisine göre daha fazla görev düşmektedir. Bu doğrultuda iç denetimin klasik bir iç denetim anlayışından çıkarak işletme varlıklarının korunması, finansal bilgilerin güvenilirliğinin sağlanması, işletmenin amaçlarına etkin ve verimli şekilde ulaşma amacına yardımcı olması gibi amaçların ötesinde işletmelerde güçlü bir kurumsal yönetim sisteminin oluşturulması ve sürdürülmesini hedef alan, bugünün yeteneklerini ve yönetim dinamiklerini göz önünde bulunduran, geleceğe yönelik yönetimsel öngörülerde bulunan ve yeni ya da bilinmeyen yönetimsel risklere karşı proaktif önlemler alabilen güncel bir iç denetim anlayışına dönüşmesi gerekmektedir. İşletme içerisinde adil, şeffaf, hesap verilebilir ve sorumluluk sahibi bir kurumsal yönetim sisteminin kurulması ve sürekliliğinin 
sağlanması için işletme içerisinde etkin ve güncel bir iç denetim fonksiyonunun tasarlanması ve sürekli olarak geliştirilmesi zorunludur.

\section{2. İç Denetimde Dijital Değişim ve Dönüşüm}

Dijital değişim ve dönüşüm, bilgi ve bilişim teknolojilerinde meydana gelen değişiklikler ve yenilikler doğrultusunda işletmelerin iş yapış şekillerinde ve süreçlerinde meydana gelen değişim ve dönüşümlerin iç denetimdeki yansımalarını ifade etmektedir.

İşletmelerin içinde bulunduğu dijital değişim ve dönüşüm süreci iç denetimde de dijital bir yaklaşıma geçilmesini gerekli kılmıştır. Dijital süreçlerin iç denetim üzerindeki etkisi temelde dijitalleşmenin getirdiği yeni risklerin iç denetimin kapsamına etkisi ve yeni teknolojilerin denetimde çalışmalarında kullanılmasının iç denetim faaliyetlerine etkisi olmak üzere iki farklı şekilde gerçekleşmiştir.

Gelişen teknolojilerin, dijital zeka ve yapay zeka uygulamalarının iş hayatında yer alması böylelikle geleneksel iş modellerinin yerini dijital iş modellerine bırakması işletmeler açısından bir yandan daha hızlı, daha üretken, daha az maliyetli iş yapabilme avantajını doğurur iken diğer yandan siber riskler vb. gibi yeni risklerin ortaya çıkmasına neden olmuştur. 2018 yılı Global Ekonomik Suç ve Hile Araştırmasına göre dijital suçlar her geçen gün giderek artmaktadır. Araştırmanın sonuçlarına göre siber suçlar en yaygın görülen hileler arasında yer almıştır ve işletmelerin \%31’i dijital hilelere maruz kaldığını belirtmiştir. (PricewaterhouseCoopers [PwC], 2018a)

İşletmeler hem içeriden hem de dışarıdan önemli siber risklerle ve dijital suçlarla karşı karşıyadır ve bu nedenle işletme yöneticileri tarafından bu riskler ciddi bir şekilde dikkate alınmalıdır (Mccollum, 2012, s.14). İç denetimde kurumsal değişim ve dönüşüm başlığı altında bahsedildiği üzere dijitalleşmenin getirdiği risklerin işletmeler açısından ciddi boyutta olması sebebiyle 2017 yılında iç kontrol bütünleşik çerçevesinde iç kontrol sistemi, dijitalleşmenin etkisi sonucunda hızla değişen ve giderek daha kompleks hale gelen iş çevresine adapte edilecek şekilde güncellenmiştir. Dolayısıyla böyle bir atmosferde iç denetimin kapsamı, odak noktaları ve işletme yönetiminin iç denetimden beklentileri de değişmiştir. Dijitalleşme ile birlikte bilginin hızlı şekilde paylaşımı denetlenmesi gereken büyük bir veriyi ortaya çıkarmış bu durum iç denetim çalışmalarının kapsamının genişletilmesini gerekli kılmıştır. Siber riskler ve dijital suçların yaygınlaşması iç denetçilerin odak noktalarından birinin de siber riskler ve dijital suçlar olmasına neden olmuş böylelikle iç denetçilerin görev ve sorumluluklarının kapsamı da genişlemiştir. Aynı zamanda söz konusu risklerin ve büyük verinin denetlenebilmesi, iç denetçilerin sürekli olarak gelişen ve değişen teknolojiyi kullanabilen, dijital süreçlere hakim olan yetkinlik ve yeterliliklere sahip olmasını da gerektirmiş böylelikle iç denetçi profilleri de dönüşüme uğramıştır. Yeni teknolojilerin, robot yazılımların, kurumsal kaynak planlama (KKP) süreçlerinin denetimde kullanımı iç denetçilere zaman ve maliyet avantajı sağlamış ve denetim çalışmalarının yürütülmesini de kolaylaştırmıştır.

Dijitalleşme ile birlikte büyük veri, veri analitiği, arttırılmış gerçeklik, bulut bilişim sistemleri, siber güvenlik, blokzincir, makine öğrenme, nesnelerin interneti, mobil teknolojiler, robotik yazılımlar vb. gibi yeni kavramların iş dünyasına hızlı bir şekilde girmesi inovatif gelişmelerin de artmasına neden olmuş hatta işletmeler için inovasyonu zorunlu hale getirmiştir. $\mathrm{Bu}$ durum işletme yöneticilerinin iç denetçilerden olan beklentilerinin artmasına neden olmuştur.

2018 yılı İç Denetim Meslek Profesyonelleri Çalışmasına göre; iç denetim fonksiyonunun proaktif bir şekilde inovasyon sürecine katkı sağlaması, hızlı bir şekilde yeni teknolojilerin avantajlarını değerlendirmesi aynı zamanda yeni teknolojilerin iç kontrol sistemleri üzerinde meydana getireceği riskleri önceden algılaması ve risklerin yönetilmesini sağlaması işletme yöneticilerinin iç denetim mesleğinden ve iç denetçilerden olan beklentileriarasında yer almaktadır. (PricewaterhouseCoopers $[\mathrm{PwC}], 2018 b)$

\section{3. İç Denetimde Kültürel Değişim ve Dönüşüm}

Kültürel değişim ve dönüşüm, günümüz Dünyasında meydana gelen değişiklikler doğrultusunda işletmelerin kurumsal kültür yapısında ve anlayışında meydana gelen değişim ve dönüşümlerin iç denetimdeki yansımalarını ifade etmektedir. 
Kurumsal kültür kavramı; bir organizasyon içerisindeki işletme sahip veya sahipleri ile diğer tüm işletme çalışanları tarafından benimsenen etik ilkeler, kurallar, prensipler, normlar, ahlâki değerler, inançlar, davranış şekilleri ve tutumlar bütününü ifade etmektedir. Organizasyonların içerisinde bulunduğu sürekli bir değişim ve dönüşüm süreci ve bu sürece bağlı olarak organizasyonların yapısında meydana gelen majör değişiklikler organizasyonların kurumsal kültür yapılarını önemli derecede etkilemektedir. Söz konusu değişim ve dönüşüm süreci bir yandan kurumsal kültür kavramının giderek daha kompleks ve denetlenmesi zor bir kavram haline gelmesine neden olur iken diğer yandan finansal ve operasyonel riskler yerine tıpkı siber riskler gibi işletmeler açısından yeni bir risk unsuru olarak kültürel riskleri ön plana çıkarmıştır. Özellikle son yıllarda işletmelerde meydana gelen suistimal ve yolsuzluk olayları ile denetim skandallarının arkasında yatan nedenlerden birinin de zayıf veya etkin olmayan kurumsal kültür yapıları olması, kurumsal kültürü işletmeler için önemli bir risk haline getirmiş ve işletmeler tarafından denetlenmesi gereken bir olgu haline dönüştürmüştür.

Kurumsal kültürün denetlenmesi ihtiyacı ise iç denetim mesleğinin kapsamında ve iç denetçilerin görev, yetki ve sorumluluklarında bir değişim ve dönüşüme sebep olmuştur. Buna göre iç denetimin kapsamı organizasyon içerisindeki kurumsal kültür sisteminin de denetimini içerecek şekilde genişletilmiş ve kurumsal kültürü denetleme görev ve sorumluluğu iç denetçilere verilmiştir. Uluslararası İç Denetçiler Enstitüsü (IIA) tarafından kurumsal kültürün denetlenmesi konusundaki sorumluluğun iç denetime verilmesinin ve işletme yönetiminin iç denetçilerden organizasyon içerisindeki kurumsal kültürü de denetlemesi yönünden bir beklenti geliştirmesinin en büyük sebebi ise organizasyonlar içerisinde iç denetim departmanlarının organizasyonun kurumsal kültürünü yakından gözlemleyen, takip edebilen, izleyen ve inceleyebilen bir pozisyonda bulunması olmuştur.

İşletmelerde kurumsal kültürde meydana gelen değişim ve dönüşümlerin iç denetime yansımaları sonucunda iç denetim faaliyetlerinin odak noktalarından birinin kurumsal kültür olması, periyodik olarak organizasyonların kurumsal kültür denetimlerinin yapılması ve yürütülen her bir denetim prosesi içerisinde diğer denetim çalışmalarıyla bütünleşik şekilde kurumsal kültürün ve kurumsal kültür açısından risk taşıyan alanların değerlendirilmesi, değerlendirilmesi, mevcut denetim prosedürlerinin ve kontrollerinin ötesinde organizasyon içerisindeki sorunların arkasında yatan sebeplerin davranışsal veya kültürel faktörlere dayanıp dayanmadığının araştırılması, organizasyon içerisindeki kurumsal kültürün etkinliğinin test edilmesi ve iç denetim anlayışının bu gereklilikleri sağlayacak şekilde değiştirilmesi gerekmektedir. Bununla birlikte iç denetçilerin kurumsal kültürün denetimi konusunda yeni iç denetim anlayışının gerekliliklerini yerine getirebilecek şekilde; kültürel ve duygusal faktörlere karşı yüksek derecede farkındalık ve kavrayış yeteneğine sahip olma, analitik-mantıksal-teknik düşünme yeteneği ile yaratıc1-psikolojik-bütünsel düşünme yeteneği arasında köprü kurabilme, kültürel zindeliğe sahip olma gibi kültürel zindelik açısından yeni yetkinlikler, beceriler ve özelliklere sahip olması gerekmektedir (Bircan, 2018, s.183). İç denetçilerin kurumsal kültür denetimi sırasında özellikle iç güdüsel yeteneklerini kullanabilme kapasitesine sahip olmaları, küçük noktalara dokunabilmeleri ve küçük noktaları birleştirerek, kombine ederek organizasyonun kurumsal kültürüne ilişkin büyük bir perspektif çizebilmeleri, geleneksel yöntem ve methodların dışına çıkabilecek yenilikçi inovatif yeteneklere sahip olmaları ve yeni iletişim becerileri geliştirmeleri kurumsal kültürün denetiminde önemli bir rol oynamaktadır. (The Institute of Internal Auditors [IIA], 2014)

\section{5. İç Denetimde Yapısal Değişim ve Dönüşüme İlişsin İç Denetçilerin Farkındalığı ve Beklentileri Üzerine Bir Araştırma}

\subsection{Araştırmanın Amacı}

İç denetimde yapısal değişim ve dönüşüm sürecine ilişkin "İç Denetçilerin Farkındalı̆̆ı ve Beklentileri Üzerine Bir Araştırma" adlı çalışmanın amacı, iç denetim alanında faaliyet gösteren meslek profesyonellerinin, iç denetimde yaşanan yapısal değişim ve dönüşüm sürecine karşı farkındalığını ölçmek ve beklentilerini değerlendirmektir. Yapılan araştırma ile iç denetimde yaşanan değişim ve dönüşüm gerçeğinin, iç denetçiler üzerindeki etkileri ve söz konusu değişim sürecine karşı iç denetçilerin bakış açıları tespit edilmeye çalışılmıştır. 


\subsection{Araştırmanın Kapsamı ve Kısıtları}

Araştırmanın ana kütlesini, özel sektörde faaliyet gösteren iç denetçiler oluşturmaktadır. Araştırmanın dönemi, 2020 yılı Şubat ayını kapsamaktadır. Tüm iç denetçilere ulaşılmasının pratikte mümkün olmaması ve ciddi zaman kaybına yol açabilmesi sebebiyle araştırma, ana kütleden tesadüfi örneklem yöntemiyle seçilen ilgili örneklem üzerinde gerçekleştirilmiş ve konu ile ilgili 51 iç denetçiye ulaşılmıştır. Araştırma konusu ve soruları ile araştırmaya katılan iç denetçilerin demografik özellikleri arasında anlamlı bir ilişkinin bulunmaması ve araştırmanın amacının, farklı iç denetçi grupları arasındaki cevapların farklılıklarını değerlendirmek değil genel olarak iç denetçilerin araştırma konusundaki eğilimlerinin tespit edilmesi ve değerlendirilmesi olması sebebiyle araştırmaya katılan söz konusu iç denetçilere yönelik herhangi bir demografik ayrıştırma yapılmamıştır. Buna göre araştırma; otomotiv, gıda, perakende, hazır giyim, enerji, bankacılık, sigorta ve reasürans, bağımsız denetim, medya, telekomünikasyon, konaklama ve futbol gibi çok farklı sektörlerde ve bölgelerde faaliyet gösteren özel sektör işletmelerinin holding ve grup şirketlerinde çalışan iç denetçiler üzerinde uygulanmıştır. Yukarıda belirtilen sektörlerde faaliyet gösteren 51 farklı iç denetim meslek profesyoneline sorular sorularla; iç denetçilerin değişim ve dönüşüme karşı tutumları, değişimi ne derece benimsedikleri ve kabullendikleri, değişim gerçeğine olan inançları, değişim ve dönüşümün gerekliliklerini iç denetim faaliyetlerine ne kadar yansıttıkları, değişim ve dönüşüm karşısında mevcut bilgi, birikim ve yetkinliklerini ne derece yeterli buldukları ve yaşanan değişim ve dönüşüm konusunda endişelerinin olup olmadığı değerlendirilmeye çalışılmıştır. Araştırmaya katılan iç denetçilerin pozisyonları; iç denetim uzman yardımcıları, iç denetim uzmanları, iç denetim kıdemli uzmanları, iç denetim müdürleri ve iç denetim direktörlerinden oluşmaktadır.

\subsection{Araştırmanın Yöntemi}

Araştırmada nicel bir yöntem olarak anket yöntemi kullanılmış ve araştırmanın verileri anket yöntemiyle toplanmıştır. Anket yöntemi olarak çevrimiçi anket yöntemi uygulanmıştır. İç denetim meslek profesyonellerinin araştırma konusuna ilişkin düşüncelerini, endişelerini ve algılarını değerlendirebilmek ve bu konuda sayısal çıkarımlara ulaşabilmek amacıyla hazırlanan anket formu, 10 sorudan oluşmaktadır. Anket formunda ikinci soru hariç olmak üzere ilk 8 soru için soru tipi olarak cevabı açık soru tekniği (Evet /Hayır) ve ikili ölçek, ikinci soru için uygun olanı işaretleme soru tekniği ve ikili ölçek kullanılmıştır. Son soru için ise çoktan seçmeli soru tekniği ve bağımsız maddelerden oluşan ölçek; maddeleştirilmiş ölçek kullanılmıştır. Çalışmada cevabı açık soru tekniğinin ağırlıklı olarak kullanılmasının sebebi, katılımcıların değişim ve dönüşüm sürecine yönelik belirlenen açık ifadelere katılım derecesini kolaylıkla değerlendirmeyi sağlamaktır. Anket soruları, yanıtlayanları belli bir fikre yönlendirmeyecek veya ön yargıya kapılmasını sağlamayacak şekilde araştırma konusuna odaklı nötr şekilde oluşturulmuştur. Anket, iç denetçiler üzerinde uygulanmadan önce soruların güvenilirliği ve anlaşılırlı̆̆ açısından deneme çevrimiçi anket uygulamasıyla da test edilmiştir. Anket sorularının cevapları, çevrimiçi anket formu raporundan elde edilen yüzdesel dağılım grafikleri ve tablolar aracılığıyla trend yüzdesi yöntemiyle analiz edilerek değerlendirilmiştir.

\subsection{Araştırmanın Bulguları ve Sonuçlar}

İç denetçiler üzerinde uygulanan anket çalışmasının sonuçlarına yönelik elde edilen sayısal veriler aşağıdaki şekilde özetlenebilir;

* Ankete katılan toplam 51 iç denetçiden 43 ’ü (\%84,3’ü) iç denetim mesleğinin sürdürülebilirliği için dönüşümün zorunlu olduğu görüşünü belirtirken 8’i (\%15,7’si) dönüşümün zorunlu olmadığını belirtmiştir.

* Ankete katılan iç denetçilerin tamamı (\%100’ü) iç denetim mesleğindeki değişim ve dönüşümün sürekli bir olgu olduğu inancindadir.

* Ankete katılan toplam 51 iç denetçiden 21'i (\%41,2'i) iç denetim çalışmalarında robotik yazılımları kullandığ belirtirken 30’u (\%58,8’i) iç denetim çalışmalarında robotik yazılımları hiç kullanmadığını belirtmiştir. 
* Ankete katılan toplam 51 iç denetçiden 40’1 (\%78,4’ü) iç denetimde kurumsal, dijital ve kültürel açıdan yaşanan değişim ve dönüşüme karşı kendisini hazır hissederken 11’i (\%21,6’sı) endişe duyduğunu belirtmiştir.

* Ankete katılan toplam 51 iç denetçiden 36's1 (\%70,6's1) bilgi, beceri ve yetkinliklerini değişen iç denetim mesleğinde yeterli görürken, 15’i (\%29,4’ü) kendisini bu konuda yeterli görmemektedir.

* Ankete katılan toplam 51 iç denetçiden 43'ü (\%84,3’ü) son 5 yıl içerisinde farklı ve yeni iç denetim tekniklerini kullandığını belirtirken, 8’i (\%15,7'si) iç denetim tekniklerini hiç değiştirmeden aynı denetim tekniklerini kullanmaya devam ettiğini belirtmiştir.

* Ankete katılan toplam 51 iç denetçiden 32'si (\%62,7'si) iç denetim faaliyeti içerisinde siber risk denetimi yaparken, 19'u (\%37,3’ü) siber risk denetimi yapmamaktadır.

* Ankete katılan toplam 51 iç denetçiden 42’si (\%82,4’ü) iç denetim çalışmaları sırasında organizasyonların kurumsal kültürle ilgili risklerini de değerlendirirken 9’u (\%17,6'sı) kurumsal kültür ile ilgili herhangi bir çalışma yapmamaktadır.

* Ankete katılan toplam 51 iç denetçiden 39’u (\%76,5’i) değişen ve dönüşüme uğrayan iç denetim faaliyetleri karşısında kendisini geliştirmek ve hazırlamak konusunda bağlı bulunduğu işletme yönetiminden destek gördüğünü belirtirken, 12’si (\%23,5’i) destek görmediğini belirtmiştir.

* Ankete katılan toplam 51 iç denetçiden sadece 7'si (\%13,7'si) siber risklerin, suistimal ve usulsüzlüklerin, kurumsal kültürün ve iç kontrollerinin etkinliğinin denetimi olmak üzere bu denetimlerin tamamı için kendini yetkin görmektedir.

Araştırma sonucunda elde edilen sayısal bulgular yorumlandığında araştırma ana kütlesini oluşturan iç denetim meslek profesyonellerinin iç denetimde yaşanan zorunlu ve sürekli bir değişim ve dönüşüm sürecinin farkında olduğu ve bunu kabullendiği söylenebilir. Ankete katılan iç denetçilerin, \%100'nün (tamamının) iç denetim mesleğinde değişim ve dönüşümü sürekli bir olgu olarak görmesi ve \%84'nün mesleğin sürdürülebilirliği için dönüşümün zorunlu olduğu ifadesine katılması bunun bir göstergesidir. Benzer şekilde iç denetçilerin \%84’ünün son 5 yıl içerisinde iç denetimde kullandığı denetim tekniklerinin değiştiğini ifade etmesi de bu sonucu desteklemektedir.

Anket sonuçları, söz konusu algının ve değişim olgusunun iç denetimde uygulamaya geçirilmesi açısından incelendiğinde ise aynı derecede yüksek oranlar görülememektedir. Örneğin robotik yazılımların iç denetçilerin yarısından fazlası yaklaşık \%59'u tarafından iç denetim faaliyetlerinde halen hiç kullanılmadığı görülürken sadece \%41'inin robotik yazılımları iç denetim faaliyetlerinde fiili olarak hayata geçirdiği görülmektedir. Benzer şekilde artık iç denetimin faaliyet kapsamı içerisinde değerlendirmesi gereken bir unsur olan siber risklerin denetim oranı da nispeten düşüktür. İç denetçilerin yaklaşık \%63'ü iç denetimin içerisinde siber risklerin de denetimi yaptığını belirtmiştir. \%37'si ise siber risk denetimi yapmadığını belirtmiştir. Bununla birlikte işletmelerin kurumsal kültürle ilgili risklerinin değerlendirilmesi açısından sonuçlar, iç denetçilerde oluşan değişim ve dönüşüm algısı ile paraleldir. İç denetçilerin \%82'sinin iç denetimle bütünleşik olarak kurumsal kültürle ilgili riskleri de değerlendirdiği görülmektedir.

İç denetçilerin değişim ve dönüşüme karşı endişeleri ve bu konuda işletme yönetiminden gördükleri destek açısından değerlendirildiğinde, ankete katılan iç denetçilerin ortalama \%25'nin, işletme yönetiminden mesleki yeterlilik ve yeteneklerini geliştirmek konusunda herhangi bir destek görmemesi sebebiyle iç denetimde yaşanan değişim ve dönüşüm sürecine karşı kendisini hazırlıklı hissetmediğini veya dijital, kültürel ve kurumsal değişime karşı endişelerinin olduğunu doğruladığı görülmektedir.

İç denetçilerin bu konudaki endişeleri ile ilişkili olan yetkinlikler konusu incelendiğinde ise iç denetçilerin kendilerini en yetkin ve yeterli hissettikleri denetim faaliyeti alanının \%92'lik oranla iç kontrollerin etkinliğinin denetimi olduğu görülmektedir. Bu durum şaşırtıcı değildir, zira iç kontrollerin etkinliğinin denetimi iç denetim faaliyetinin varoluşundan bu yana mevcut olan ve iç denetçiler tarafından standart bir iç denetim faaliyeti içerisinde her zaman ilk olarak yapılan iç denetim prosedürlerinden biridir. İç kontrollerin etkinliğinin denetimini \%86’lık bir oranla suistimal ve usulsüzlüklerin 
denetimi ve \%55'lik bir oranla kurumsal kültürün denetimi takip etmektedir. İç denetçiler kendilerini en az ise siber risklerin denetimi konusunda yeterli görmektedir ve iç denetçilerin sadece \%7'si bu denetim faaliyetlerinin hepsini iç denetim faaliyetleri içerisinde uygulama konusunda kendisini yeterli hissettiğini belirtmektedir.

Anket sonuçları bir bütün olarak değerlendirildiğinde iç denetçilerde zihinsel olarak bir değişim ve dönüşüm farkındalığının ve bilincinin, iç denetim faaliyetlerinde fiili olarak uygulamaya geçirilme aşamasında bazı eksiklikler olmakla birlikte yüksek oranda gelişmiş olduğu söylenebilir. Bununla birlikte değişimin getirdiği yeni denetim anlayışlarının iç denetim faaliyetlerine adapte edilmesi ve bu konuda iç denetçilerin sahip olması gereken yetkinliklerin geliştirilmesi konusunda çeşitli eksikliklerin olduğu da açıktır.

Değişim ve dönüşüm sürecinin iç denetçiler tarafından iç denetim uygulamalarının tamamına yansıtılabilmesi için işletme yönetimlerinin, iç denetçileri değişim ve dönüşüm sürecine karşı hazırlamaları, iç denetçilere mesleki bilgi, beceri ve yeteneklerini geliştirme konusunda fırsat vermeleri ve destek olmaları oldukça önemlidir. Bu yüzden yeni ve gelişmiş teknolojik araç ve gereçler işletme yönetimi tarafından organizasyonlara kazandırılmalı ve iç denetçilerin kullanımına sunularak iç denetim faaliyetlerinin içine dahil edilmeli ve iç denetçilerin yeni teknolojileri, yapay zekâ ve dijital zekâ uygulamalarını en iyi şekilde kullanabilmesi için gerekirse kendilerine bu konuda eğitim verilmesi veya işletme yönetimi tarafından eğitim desteğinin sağlanması gerekmektedir. İç denetçilerin özellikle siber risklerin denetimi ve kurumsal kültürün denetimi konusunda geliştirilmesinin ve mevcut yetkinliklerinin arttırılmasının gerekli olduğu görülmektedir.

İç denetimde yapısal değişim ve dönüşüm süreci hakkında iç denetçilerin algıları ve beklentilerine ilişkin anket soruları ve sonuçları aşağıda grafikler yardımıyla da aşağıda gösterilmiştir;

1)"Transform or Die" ifadesine katilıyor musunuz?

51 yanıt

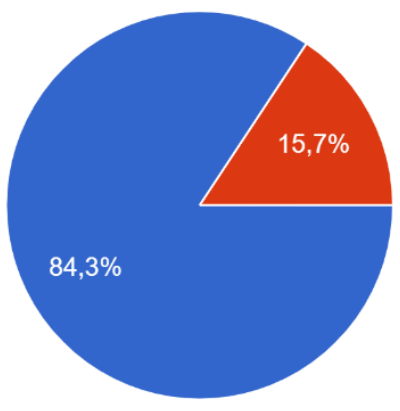

EVET

HAYIR 
2)iç denetimde yapısal değişim ve dönüşüm sizce geçici bir trend midir yoksa sürekli bir olgu mudur?

49 yanit

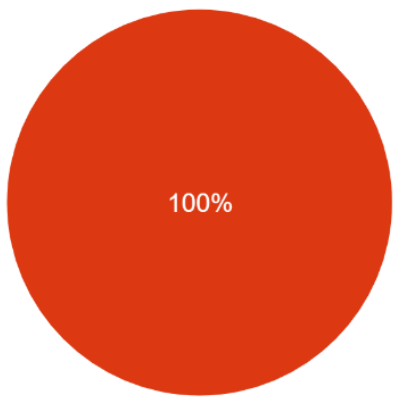

Geçici bir trenddir

Sürekli bir olgudur.

3)iç denetim çalışmalarınızda robotik yazılımları hiç kullandınız mı?

51 yanıt

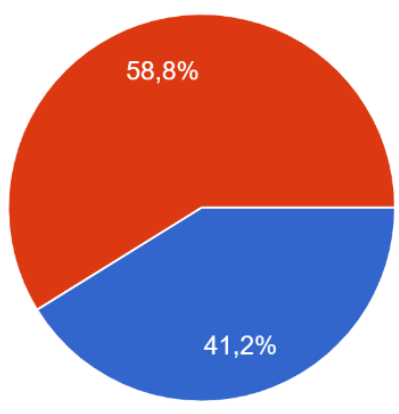

EVET

HAYIR

4)iç denetimde yaşanan teknolojik/dijital, kültürel ve kurumsal dönüşüme karşı endişeleriniz var mı ? 51 yanit

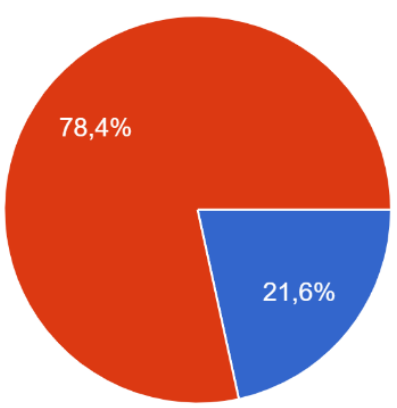

HAYIR 
5)Bir meslek profesyoneli olarak mevcut yetenek ve yetkinliklerinizi değişen iç denetim anlayışı için yeterli görüyor musunuz?

51 yanıt

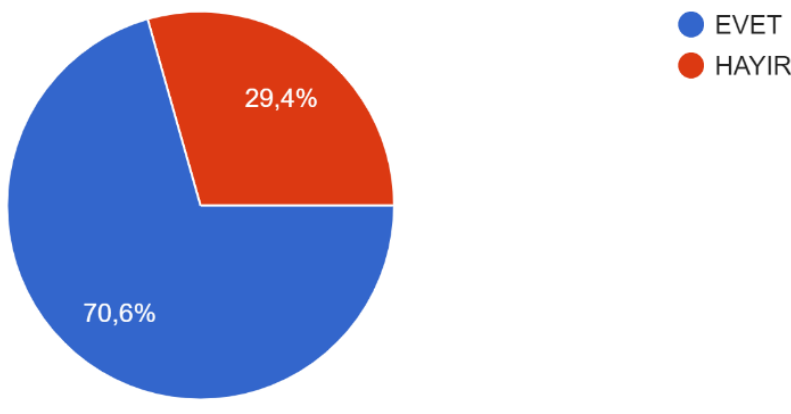

6)Son 5 yıl içerisinde iç denetim kapsamında uyguladığınız denetim teknikleri değişti mi? 51 yanıt

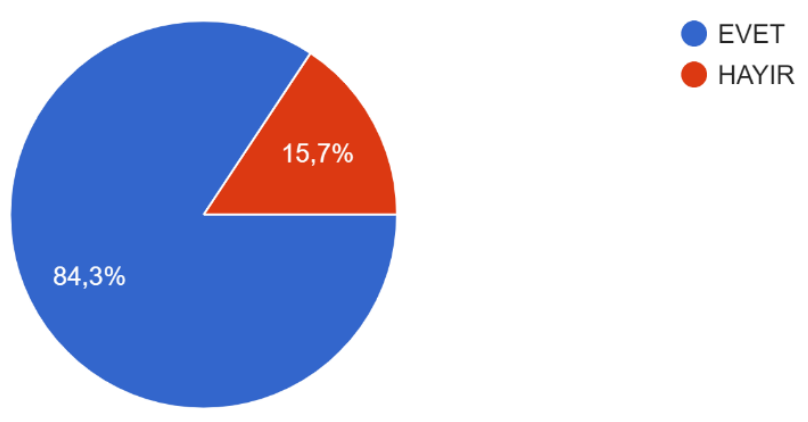

7)íç denetim çalışmalarınız kapsamında siber risklerin denetimini yapıyor musunuz? 51 yanit

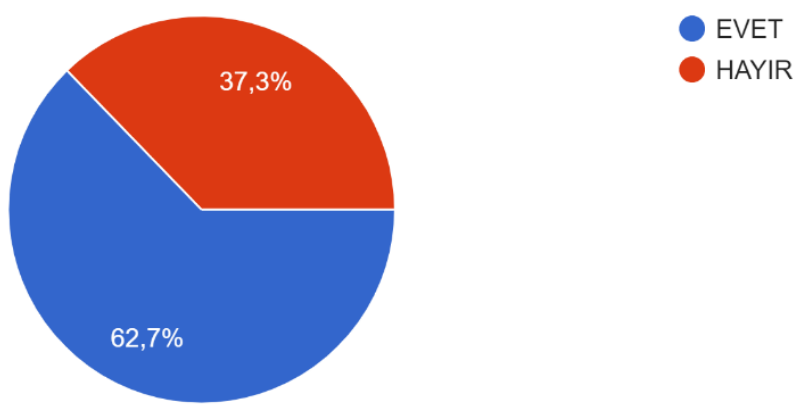


8)iç denetim çalışmalarınız kapsamında klasik iç denetim faaliyetleri ile bütünleşik olarak denetlediğiniz organizasyonların kurumsal kültür ile ilgili risklerini de değerlendiriyor musunuz? 51 yanit

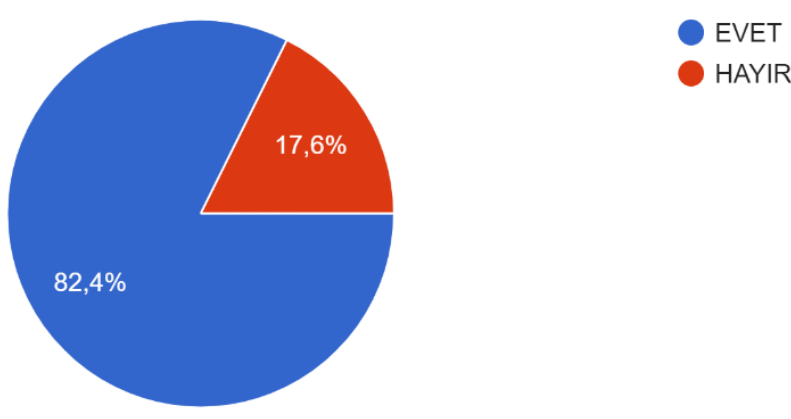

9)iç denetimdeki değişime ve dönüşüme karşı kendinizi hazırlamak, mesleki yeterlilik ve yeteneklerinizi geliştirmek konusunda işletme yönetiminden gerekli desteği görüyor musunuz? 51 yanit

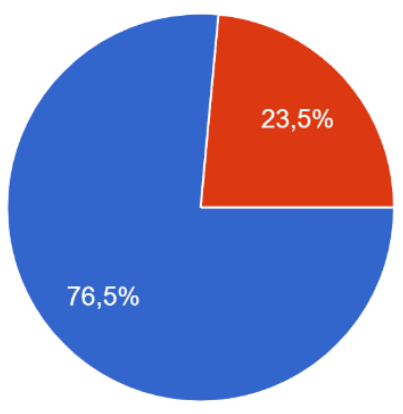

EVET

HAYIR

10)Aşağıdaki kavramlardan hangilerinin denetimi konusunda kendinizi yeterli görüyorsunuz ?Bir veya birden fazla seçeneği işaretleyebilirsiniz.

51 yanıt

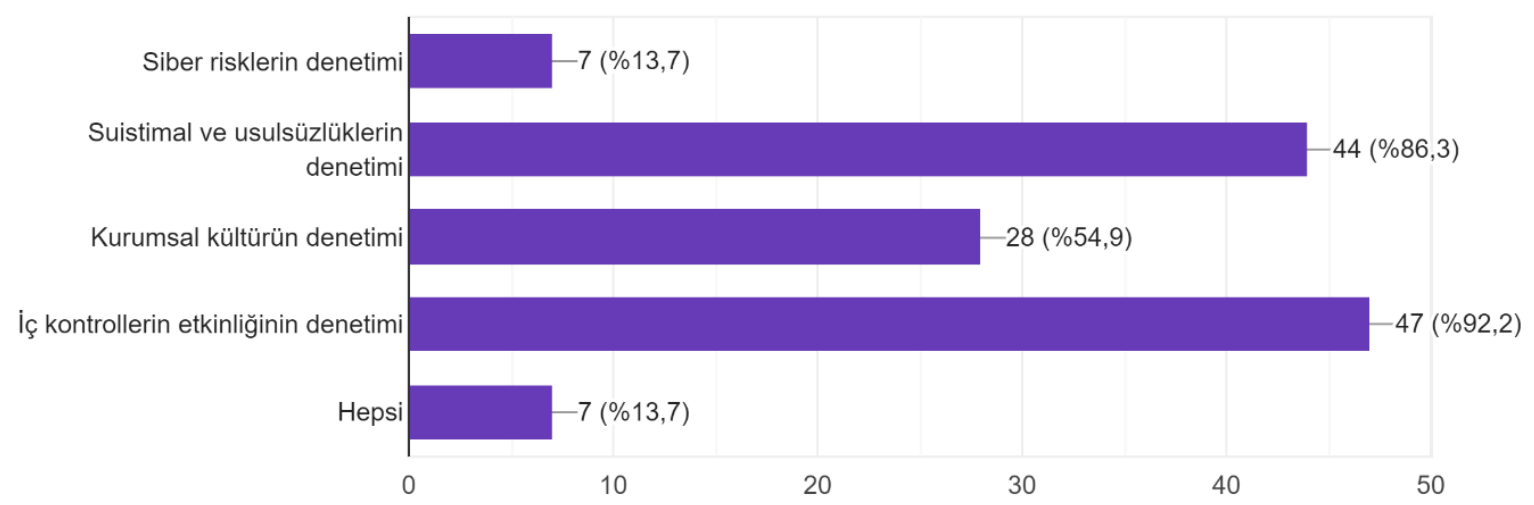




\section{Sonuç}

Günümüzde iç denetimin eskiden olduğu gibi klasik iç denetim faaliyetlerine devam ederek geçerliliğini koruması mümkün değildir. Yeni Dünya düzeninin getirdiği yenilikler, iç denetim anlayışının standart bir denetim anlayışından farklı bir denetim anlayışına dönüşmesini zorunlu kılmıştır.

Bilgi ve bilişim teknolojilerinde yaşanan gelişmeler iş yapış şekillerini değiştirmiş, yeni ve farklı teknolojilerin iş hayatına girmesine neden olmuş, işletmeler açısından yeni riskleri ve denetlenmesi gereken yeni unsurları ortaya çıkarmış ve işletme yönetiminin iç denetçilerden olan beklentilerini değiştirmiştir. Söz konusu değişim ortamı; iç denetim faaliyetlerinin, fonksiyonlarının ve kapsamının, iç denetçilerin sorumluluklarının, iç denetçi profillerinin ve bir bütün olarak iç denetimin yapısının değişmesine neden olmuştur.

İç denetim faaliyetlerinin değişen koşullar karşısında yeterli olabilmesi için iç denetimin; işletme varlıklarının korunması, etik kural, politika ve prosedürlere uygunluğun sağlanması, işletmenin amaçlarına etkin ve verimli şekilde ulaşmasının sağlanması ve işletme içerisindeki iç kontrol sistemlerinin etkinliğinin değerlendirilmesi amaçları dışında, işletme içerisinde suistimal ve usulsüzlüklerin önlenmesi, siber risklerin değerlendirilmesi, kurumsal kültür yapısının incelenmesi ve kurumsal kültür ya da yönetim risklerinin değerlendirilmesi amaçlarına yönelik faaliyetleri de içermesi gerekmektedir.

Yaşanan değişim ve gelişmeler, iç denetimin fonksiyonlarına yeni fonksiyonların (suistimal ve usulsüzlükleri önleme, siber riskleri ve kurumsal kültürü değerlendirme) eklenmesine dolayısıyla iç denetim faaliyetlerinin çeşitlenmesine (suistimal ve usulsüzlüklerin denetimi, kurumsal kültür denetimi, siber risklerin denetimi) ve iç denetimin kapsamının genişlemesine neden olmuştur. Ayrıca işletme yönetimi açısından artık en önemli konuların; yeni teknolojilere karşı organizasyonun gerekli araç ve yeteneklere nasıl sahip olacağı, yeni riskleri nasıl yöneteceği, geleceği nasıl öngöreceği ve yeni nesil iş modelleri ile yetenekleri organizasyona nasıl katacağı gibi konular olması sebebiyle iç denetimin statik bir yapıdan daha dinamik bir yapıya dönüşmesi, iç denetim fonksiyonunun inovatif olması ve iç denetim faaliyetlerinin geleceği öngörme fonksiyonuna hizmet edecek şekilde yeniden tasarlanması gerekmektedir. Tüm bu bilgiler doğrultusunda yeni iç denetim anlayışının taşıması gereken özellikler aşağıdaki gibi sıralanabilir;

- Dinamik bir yapıya sahip olma

- Standart iç denetim faaliyetleri dışında işletme içerisindeki kurumsal kültürün, siber veya diğer dijital risklerin, suistimal ve usulsüzlüklerin, yapay zekâ ve dijital zekâ uygulamalarının denetimi konusunda da bilgi sahibi olma ve standart iç denetim faaliyetleri ile bütünleşik olarak söz konusu denetim faaliyetlerini de yürütme

- Yeni teknolojileri (robotik yazılımlar, ERP uygulamaları, veri analitiği, bulut bilişsim, siber güvenlik vb.) ve yetenekleri (yapay zekâ, dijital zekâ ve süreç zekâsı uygulamaları) iç denetim sürecine dahil etme ve iç denetim faaliyetlerinde kullanabilme

- Veri analitiğini stratejik bir karar mekanizması olarak kullanabilme

- Geleceği öngörebilme ve gelecekteki risklere karşı proaktif olma

- Yeni teknoloji ve yetenekleri organizasyona kazandırma konusunda öncü olma ve işletme yönetimine bu konuda danışmanlık hizmeti verme

- Yeni teknolojinin getirdiği avantaj ve dezavantajları önceden değerlendirebilme ve yeni iş risklerini yönetebilme

- Yeni denetim yaklaşımlarına ve tekniklerine karşı açık olma

- İnovatif bir anlayışa ve inovatif iç denetim fonksiyonlarına sahip olma

- Sürekli olarak değişim ve yenilikleri takip etme ve sürekli gözetim faaliyetinde bulunma 
İç denetim faaliyetlerinin yukarıda belirtilen şekilde bir dönüşüme uğraması için ise temel görev iç denetçilere düşmektedir, çünkü iç denetim faaliyetlerinin belirtilen özelliklere sahip olabilmesi ancak iç denetim faaliyetlerini yürütecek olan meslek profesyonellerinin yani iç denetçilerin mevcut bilgi, beceri ve yetenekleri ile denetim anlayışlarının değişmesi ile mümkün olabilecektir. Hem iç denetim mesleğindeki değişime ayak uydurabilmek hem de işletme yönetiminin iç denetçilerden olan yeni beklentilerini karşılayabilmek için yeni ve güncel bir iç denetçi profiline ihtiyaç söz konusudur.

Türkiye İç Denetim Enstitüsü (TIDD) tarafından “Günümüz Dünyasında Değişimin Öncüsü Olmak” temasıyla düzenlenen XXIII. Uluslararası Türkiye İç Denetim Kongresi’nde TUSİAD Yönetim Kurulu Başkanı Sn. Simone Kaslowski tarafindan değişen koşullar doğrultusunda geleceğin iç denetçi profili; "yeni teknolojileri iyi bilen, bu teknolojilerin ortaya çıkardiğg potansiyel risk ve firsatlart bilen, analitik düşünme yeteneğine sahip, güçlü iletişim beceresine sahip, farkl birimler arasında iletişim kurabilen, değişime açık ve yenilikçi kişiler" olarak belirlenmiştir. Kaslowski tarafından belirtilen özellikler iç denetim mesleğindeki değişim ve yenilikler ile birlikte dikkate alındığında yeni iç denetçilerin; yeni ve gelişen teknolojileri iyi kullanabilen, bu teknolojilerin ortaya çıkardığı potansiyel risk veya fırsatların farkında olan, yeni teknolojilere ve farklı denetim tekniklerine kısa sürede adapte olabilen, dijital zindeliğe sahip, yeni risklere karşı proaktif davranabilen, güçlü iletişim beceresine sahip, stratejik karar verme yeteneğine ve analitik düşünme beceresine sahip, sezgi ve kavrayış yeteneği yüksek, geleceği öngörebilen, inovatif denetim anlayışına inanan, yeni gelişmelere karşı meraklı, sürekli gelişime önem veren, yeni yeteneklerin kazanımı konusunda istekli, değişime açık ve yenilikçi kişiler olması gerektiği söylenebilir.

İç denetçilerin kendilerini değiştirme ve dönüştürme konusunda, yeni iç denetim anlayışının gerektirdiği özellikleri karşılayacak şekilde bir eylemde bulunması ise tamamıyla değişim ve dönüşüm konusundaki algı ve beklentilerine göre şekillenmektedir. İç denetçilerin bu yöndeki algı ve beklentilerini anlamaya yönelik olarak 51 iç denetçi üzerinde uygulanan anket çalışmasının sonuçları, iç denetimdeki değişim ve dönüşüm açısından iç denetçilerin zihninde değişimin ve dönüşümün kaçınılmaz bir gerçek olduğu ve sürekli olarak devam edeceği konusunda yüksek oranda bir farkındalı̆̆ın oluştuğunu göstermektedir. Bununla birlikte anket sonuçları söz konusu algının ve değişim olgusunun iç denetimde uygulamaya geçirilmesi açısından incelendiğinde aynı derecede yüksek oranlar görülememektedir. Robotik yazılımların iç denetim faaliyetlerinde kullanılma oranları ilişkin ana kütleden elde edilen sayısal veriler daha düşük orandadır. Benzer şekilde iç denetimin faaliyet kapsamı içerisinde artık değerlendirmesi gereken yeni bir unsur olan siber risklerin denetim oranı da nispeten düşüktür. Bununla birlikte işletmelerin kurumsal kültürle ilgili risklerinin değerlendirilmesi açısından sonuçlar, iç denetçilerde oluşan değişim ve dönüşüm algısı ile paraleldir. İç denetçilerin \%82'sinin iç denetimle bütünleşik olarak kurumsal kültürle ilgili riskleri de değerlendirdiği görülmektedir.

İç denetçilerin değişime kendilerini adapte edebilmeleri için bu konuda bir farkındalıklarının olmasının yanı sıra değişime yönelik mesleki bilgi, beceri ve yeteneklerini geliştirebilecek bir ortama sahip olmaları ve bu konuda destek görmeleri de oldukça önemlidir. Anket sonuçları, değişim ve dönüşüm konusunda iç denetçilerin işletme yönetiminden gördükleri destekle doğru orantılı olarak az da olsa değişime karşı endişeleri olan veya değişime karşı kendini yeterli ya da hazırlıklı görmeyen bir iç denetçi varlığına işaret etmektedir. Anket sonuçları doğrultusunda, iç denetçilerin kendilerini en yetkin ve yeterli hissettikleri denetim faaliyeti alanının iç kontrollerin etkinliğinin denetimi olduğu görülmektedir. İç denetçilerin kendilerini en yetersiz gördükleri alan ise siber risk denetimi olarak karşımıza çıkmaktadır.

Sonuç olarak, anket sonuçları bir bütün olarak değerlendirildiğinde iç denetçilerde zihinsel olarak bir değişim ve dönüşüm farkındalığının ve bilincinin, iç denetim faaliyetlerinde fiili olarak uygulamaya geçirilme aşamasında bazı eksiklikler olmakla birlikte yüksek oranda gelişmiş olduğu söylenebilir. Değiş̧im ve dönüşüm sürecinin iç denetçiler tarafından iç denetim uygulamalarının tamamına yansıtılabilmesi için işletme yönetimlerinin, iç denetçileri değişim ve dönüşüm sürecine karşı hazırlamaları, iç denetçilere mesleki bilgi, beceri ve yeteneklerini geliştirme konusunda firsat vermeleri ve destek olmaları oldukça önemlidir. Bu yüzden yeni ve gelişmiş teknolojik araç ve gereçler işletme yönetimi tarafından organizasyonlara kazandırılmalı, iç denetçilerin kullanımına sunularak iç denetim faaliyetlerinin içine dahil edilmeli ve iç denetçilerin yeni teknolojileri, yapay zekâ ve dijital zekâ uygulamalarını en iyi şekilde kullanabilmesi için gerekirse kendilerine bu konuda eğitim verilmesi veya işletme yönetimleri tarafından ilgili eğitim desteğinin kendilerine sağlanması 
gerekmektedir. İç denetçilerin özellikle siber risklerin denetimi ve kurumsal kültürün denetimi konusunda geliştirilmesinin ve mevcut yetkinliklerinin arttırılmasının gerekli olduğu görülmektedir.

Hakem Değerlendirmesi: Dıș bağımsız.

Çıkar Çatışması: Yazarlar çıkar çatışması bildirmemiştir.

Finansal Destek: Yazarlar bu çalışma için finansal destek almadığını beyan etmiştir.

Peer-review: Externally peer-reviewed.

Conflict of Interest: The authors has no conflict of interest to declare.

Grant Support: The authors declared that this study has received no financial support.

\section{Kaynakça}

Aysan, M.A. (2007). Muhasebe ve kurumsal yönetim, Muhasebe ve Finansman Dergisi, 35, 17-23.

Adiloğlu,B., Öner,S. (2019). İşletmelerde kurumsal risk yönetimi ve iç denetime farklı bir bakış açısı: 5S uygulaması. İstanbul Üniversitesi İsletme Fakültesi Muhasebe Enstitüsü Dergisi, 61(2), 67-82.

Bircan, G., (2018). İç denetimde kurumsal kültür denetimi. Muhasebe ve Denetime Bakış Dergisi, 55, 175-190.

Bozkurt, N., (2010). Muhasebe denetimi. İstanbul: Alfa Yayınları.

Clemens, D., Rick, N., (2017). Leveraging relationships: internal audit implemented a four- step cycle to help unsure a healthy corporate culture. Internal Auditor, 74(2), 62-63.

Güredin, E., (2014). Denetim ve güvence hizmetleri. İstanbul: Türkmen Kitabevi.

Karakaya, G. (2018). COSO kurumsal risk yönetimi- riskin strateji ve performansla uyumlaştırılmasına ilişkin düzenleme çerçevesinde getirilen güncellemeler. Denetişim, 18, 17-18.

McCollum, T. (2012). Digital crimes on the rise. Internal Auditor, 69(1), 14-27.

PricewaterhouseCoopers, (2011). Internal audit matters: critical to all successful organizations. Retrieved from https://www.pwc.co.uk/ assets/pdf/internal-audit-matters.pdf, (30.01.2020)

PricewaterhouseCoopers, (2018a). Global economic crime and fraud survey. Retrieved from https://www.pwc.com/gx/en/forensics/ global-economic-crime-and-fraud-survey-2018.pdf, (05.01.2020)

PricewaterhouseCoopers, (2018b). State of the internal audit profession study-moving at the speed of innovation: the foundational tools and talents of technology-enabled internal audit. Retrieved from https://www.pwc.co.uk/audit-assurance/assets/pdf/moving-at-thespeed-of-innovation.pdf, (29.01.2020)

Sabuncu, B., (2017). İşletmelerde iç denetim ve iç kontrol ilişkisi. C.Ü. İktisadi ve İdari Bilimler Dergisi, 18(2), 161.

The Institute of Internal Auditors (2014). Culture and the role of internal audit-looking below the surface. Retrieved from https://www. iia.org.uk/media/598939/0805-iia-culture-report-1-7-14-final.pdf, (06.01.2020)

The Institute of Internal Auditors (2019). Board briefing: Culture and the role of internal audit. Retrieved from https://www.iia.org.uk/ resources/audit-committees/board-briefings/board-briefing-culture-and-the-role-of-internal-audit/, (06.01.2020).

Türkiye İç Denetim Enstitüsü (2010). Uluslararası iç denetim standartlart- uluslararası mesleki uygulama çerçevesi (UMUÇ). İstanbul: Print center.

Türkiye Kurumsal Yönetim Derneği (2020). Kurumsal yönetim ilkeleri nedir. Erişim adresi http://tkyd.org/tr/sss.html. 
